\title{
The Royal Citadel of Messina. Hypothesis of architectural restoration for the conservation and use
}

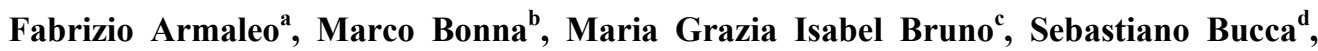
Valentina Cutropia ${ }^{\mathrm{e}}$, Nicola Faziof, Luigi Felice ${ }^{\mathrm{g}}$, Federica Gulletta ${ }^{\mathrm{h}}$, Vittorio Mondi, Elena Morabito ${ }^{1}$, Carmelo Rizzo ${ }^{\mathrm{m}}$

${ }^{a}$ ESEMeP, Messina, Italy, fabrizioarmaleo@ @otmail.it, ${ }^{b} E S E M e P$, Messina, Italy, marcobonna@email.it, ${ }^{c} E S E M e P$, Messina, Italy, mariag_bruno@hotmail.it, ${ }^{\mathrm{d}} \mathrm{ESEMeP}$, Messina, Italy, sebastianobucc@gmail.com, ${ }^{\mathrm{e}} \mathrm{ESEMeP}$, Messina, Italy, valentina.cutropia@hotmail.it, ${ }^{\mathrm{f}} \mathrm{ESEMeP}, \mathrm{Messina}$, Italy, nicolas2003@ hotmail.it, ${ }^{\mathrm{g}}$ ESEMeP, Messina, Italy, luigifelice@alice.it, hESEMeP, Messina, Italy, federicagulletta@ hotmail.it, iESEMeP, Messina, Italy, vittoriomondi@hotmail.com, ${ }^{\mathrm{E} E S E M e P, ~ M e s s i n a, ~ I t a l y, ~ m i l i g r e e n @ l i b e r o . i t, ~}{ }^{\mathrm{m}} \mathrm{ESEMeP}, \mathrm{Messina}$, Italy, carmelorizzo84@gmail.com

\begin{abstract}
The hypothesis of architectural restoration wants to ensure the conservation and the use of the Royal Citadel through a conscious reinterpretation of the work and a cautious operation of image reintegration. The Royal Citadel of Messina, wanted by the King of Spain Charles II of Habsburg, was designed and built, at the end of the XVII century, by the military engineer Carlos de Grunenbergh. It is a "start fort" located at the entrance of its natural Sickle port, that is a strategic place for controlling the Strait of Messina, the port and especially the people living here. The project is neither retrospective or imitative of the past forms, nor free from the constraints and guidelines resulting from the historical-critical understanding, but conducted with conceptual rigor and with the specific aim of transmitting the monument to the future in the best possible conditions, even with the assignment of a new function.
\end{abstract}

Keywords: Restoration, conservation, reuse, urban-archaeological park.

\section{Introduction}

The experience of design experimentation (Project Work) started within the course of "Technician for the Conservation and Reuse of Cultural Heritage" by ESEMeP (Provincial Agency for Building School of Messina). The work was based on both critical-historical understanding of the investigated object and the knowledge of its physical and material consistency. All the direct and indirect measurements, the following graphic rendering and the investigations in situ, have allowed to interpret critically the demands of conservation dictated by the factories, today abandoned, hidden and unknown, gradually defaced and, at last, forgotten. The knowledge process was introductory to reach the formulation of a hypothesis concerning the Restoration of the ancient fortification, in total respect of the characters that distinguish it.

\section{The Royal Citadel of Messina}

The fort overlooking the Strait of Messina, area of historical and geographical value of the entire Mediterranean Basin, legendary place of sea crossings since before the birth of the myth of Scylla and Charybdis, runs strategically along the root of the sickle shaped area of Messina or San Raineri's peninsula. 




Fig. 1- Juan Ruiz, View of Messina, 1748 ca. Oil on silvered copper, cm 21 x 41,7

The work was designed by the military engineer Carlos de Grunembergh and commissioned by the King of Spain, Charles II of Habsburg, in 1679. Grunenbergh's proposal provides for the building of a star fort with five Bastions, separated from the city by an artificial isthmus and from the mainland through a series of channels that exploited the tides and currents of the Strait. It had to become the most important fortification among those already existing on the territory of Messina, as the sixteenth century walls of Charles V, St Salvatore, Gonzaga, Castellaccio, Tower Victoria and Roccaguelfonia fortresses, guaranteeing the control of the Strait of Messina, and above all of the population often in fighting against the Spanish power.

According to Grunenberg's project, the Royal Citadel had to be organized as follows: two series of Pavilions had to raise around the nucleus of the Place of Arms, used by military troops stationing there, and these were protected by pentagonal walls, the so-called Curtains, provided with gunports towards the waterfront and the city; the Curtains connected the five Bastions (from the South to the North: St. Stephen, St. Charles, Grunenbergh(after called Norimberga), St Francis and San Diego); the Southern front was further protected by the forward curtain (or Opera a Martello), by St. Stephen's and St. Charles' Counterguards, by the St Teresa's Ravelin, the main access to the fortification, by Falsebraghe on the sea fronts and to the North, and finally by the Ravelin of Porta Grazia, a secondary access to the Citadel.

\subsection{Historical notes}

The process of knowledge of the Royal Citadel began studying bibliographic and iconographic sources.

A first analysis of the origins of the plan of the fortification and of the structural elements that compose it allowed us to date it back to the socalled fortifications "start fort" or "trace Italienne". Subsequent investigations and insights on cultural models of reference that are the fortifications built previously the Real Citadel in Europe, with particular reference to those of the Flemish and French schools, have allowed to hypothesize that the Grunenbergh's work is a unicum because it embodies the most important characters of the two schools that are the construction techniques adapted to the site, the importance of the star bastioned plan and the ability to withstand sieges, prolonging them by adding external buildings to the main system. The location of the Royal Citadel allows the application of military construction techniques hitherto known by the military Flemish engineers, who made their fortifications on flat, sandy and marshy territories and favored regular and symmetrical buildings.

This is maybe the reason of building a fortification having foundations con empalachones, as Grunenbergh indicated in one of his drawings in 1681 and a stellar system with 
five Bastions, reinforcing them with the same number of Knights, which had a polygonal form in front of the city while the remaining had a cylindrical one. Of French origin is the technique that allowed the fortification to extend enemy sieges, in this case, any revolt of the population of Messina.



Fig. 2- Carlos de Grunenbergh, La ciudadela de Messina y su contextualización en la ciudad, 20 de junio de 1686, Valladolid, Archivo General de Simancas, MPD XI-30 (XI-29)

A precise defensive system of buildings was conceived, located between Messina and the Citadel: a vast sloping glacis that protected a covertway behind a wide ditch, two Counterguards with the battlements, a second covertway, and finally the Bastions with embankments and the Knights stood above them with their respective battlements.

The Royal Citadel would thus presented itself as an impregnable fortress, an imposing symbol of the Spanish rule over Messina.



Fig. 3- Carlos de Grunenbergh, La ciudadela de Messina (detail of the defensive system), 30 de abril de 1681, Valladolid, Archivo General de Simancas, MPD XXI-71 (II-5)

\subsection{Timeline of the executive phases}

From the study of Grunenbergh's design it was possible to derive the constructive evolution of the Royal Citadel.

The construction of the fort began in 1681 with the raising of the Curtains of connection and of the walls of two of the five Bastions forming the defensive complex: St Stephen's Bastion and St Diego's Bastion. In 1684 there were already made: the works for the completion of the defensive walls, the remaining Bastions and the constitution of the Curtains between these, the Knights and the respective Counterguards; the Opera a Martello; St Teresa's Ravelin and the Falsebraghe facing the harbor; while the moats appeared almost completed in the North and in the South of the entire work. Among all the projected Pavilions only six were built on the Southern part of the Place of Arms between the Spanish and the Austrian rules.

The Citadel was incomplete, although Grunenbergh's design of 1686 would depict it complete.

The situation remained unchanged until 1770, when the Opera Carolina was added and dedicated to the Archduchess of Austria; it was localized within the ditch that connected through bridges the city to St Teresa's Ravelin and so to the Citadel.

On the whole there were no substantial changes to Grunenbergh's original project, as the reliefs made by the Civil Engineers in the late nineteenth century, where secondary artifacts appeared and remained intact until 1908. Among these the so called Cisternone, that still exists and it is toward the Strait, next to the St Stephen's Counterguard, probably on previously buildings.

Other insights on cartographic documents and written testimonies confirmed that the Citadel had no serious damages in the earthquake and tsunami that devastated the city of Messina in 1908; the bulk of the fort and the correct installation, evidence of a careful work of high military engineering, held out against the known shock of $\mathrm{XI}^{\circ}$ on the Mercalli scale. In contradiction to its integrity and despite the natural disasters that hit the places, unfortunately there was a devastation, both for carelessness and negligence, manifested during the Fascist period, in occasion of the designation of the architect Angelo Mazzoni for the reconstruction of the Central and Maritime Station of Messina 
in 1939. In fact, in order to the realization of naval cradles used by the railways, all the artificial moats were closed, St Charles', Grunenbergh's and St Francis' Bastions were razed to the ground with their Knights and the Curtains of connection that faced the harbor; a road was also built between the urban area and the sickle, extended to the entire fortified area, thus further dismembering the factories that survived natural disasters. The state of destruction continued in the following years with a real intervention of disfigurement of the landscape.

A careful study of the plans traces back to a concrete date, that is 1969 , when four of the six Pavilions and the Northern Ravelin were razed and replaced by sheds and instrumentation for docking boats, while works of disposal, as the incinerator, were inserted in the South between the Opera Carolina and St Stephen's Counterguard. The pentagonal Place of Arms became the fleet of the police and other warehouses and various workshops were leant to the remains of the Citadel.

\subsection{Current situation}

The knowledge phase carried on studying the physical and material consistency of the fortification, also through a campaign of direct and indirect surveys and investigations in situ.

The area on which the remains of the fort stand is in a state of almost total neglect and decay, making it invisible to the population of Messina and not easily accessible to visitor.

The use of digital instruments, such as the GPS station and the Laser Scanner, have accelerated the time taken for the metric survey of buildings and, supporting the direct surveys, have improved the accuracy of the measurements and the final rendering of the studied object, in particular focusing on the St Diego's Bastion, the Curtains connected to it, the two Pavilions and the Cisternone.

These reliefs have been attached to those previously done in occasion of a project of redevelopment of the site, conducted by the Superintendence BCA of Messina in 2003.

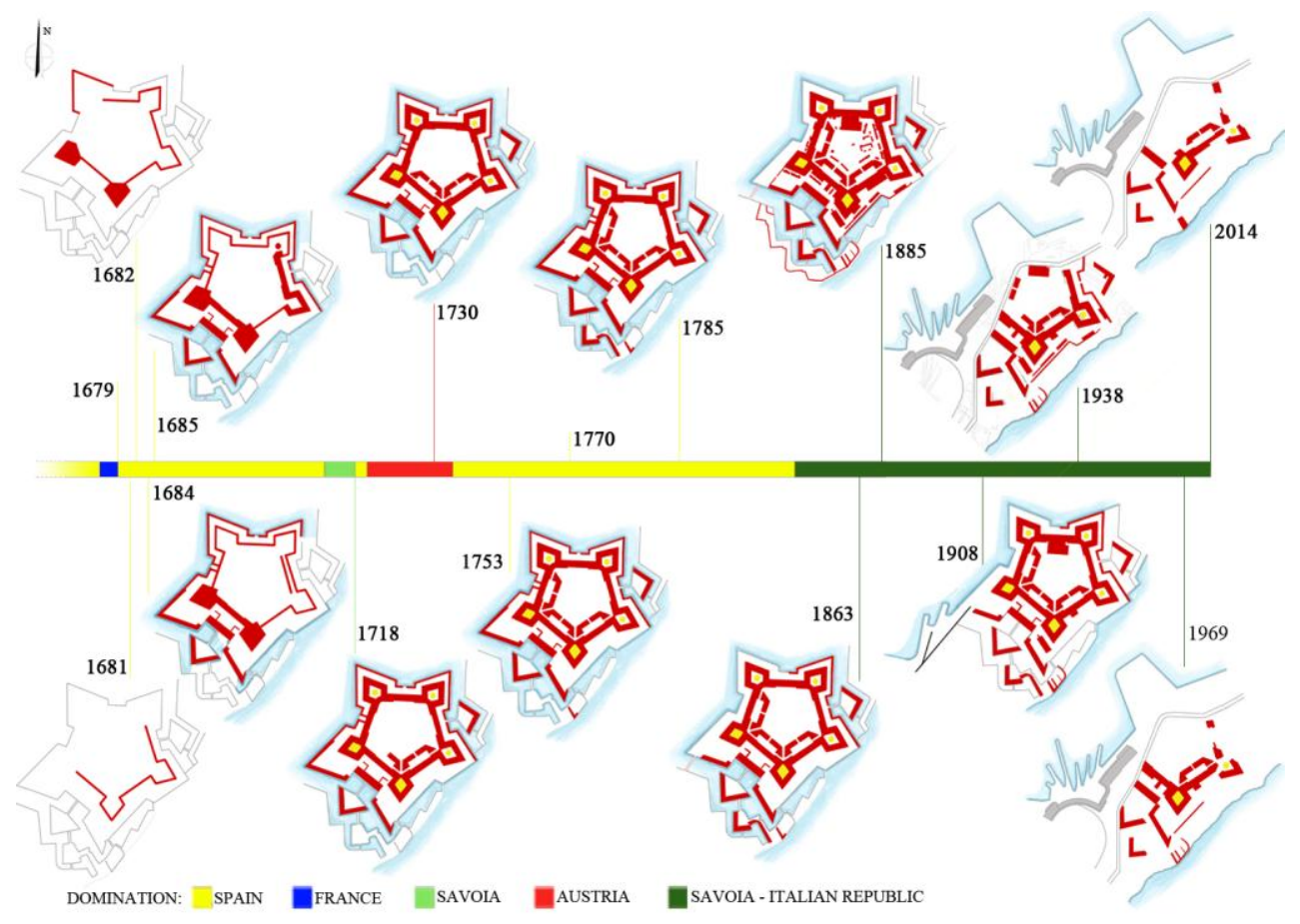

Fig. 4- Timeline of the executive phases from 1679 to 2014 (Image of the authors, 2014) 
Lacking of several portions and having evident degradations, the actual situation of the Royal Citadel is as follows, from South to North: the buildings almost completely intact are the Opera Carolina, the St Teresa's Ravelin, the Opera a Martello, the St Stephen's Counterguard, Bastion and Knight, the Cisternone and the Eastern Pavilions; though their volumes are well recognizable, the dismembered ones are the Curtain that connects the St Stephen's and St Diego's Bastions, the Knight of San Diego, the Curtain that connected the St Diego's and St Francis' Bastions, and finally a part of the masonry of the Curtain between the Grunenbergh's and St Francis' Bastions.

The metric and morphological measurements showed that the bulk of the Citadel has exterior walls with scarp thicker than the interior ones (about $5 \mathrm{~m}$ ), in order to improve the resistance to heavy artillery; following the same purpose, the internal configuration composed by tunnels and vaulted spaces. The use of recovered materials on site and the speed of execution and maintenance of the structure lead back to the modus operandi followed to raise the defensive walls, that is a mixed rustic masonry, made of regular rows, covered by a curtain of brick and Geoelectric and seismic surveys, carried out over a distance of $37 \mathrm{~m}$ between the St Teresa's and the Opera a Martello and part of the St daubed with lime mortar, while the cantonal of the Bastions are strengthened by blocks of hewn stones; there is at last a semicircular torus that runs around the walls and frames them Ravelin Stephen's Counterguard, confirmed the composition of soft rocks and/or sandy soil and

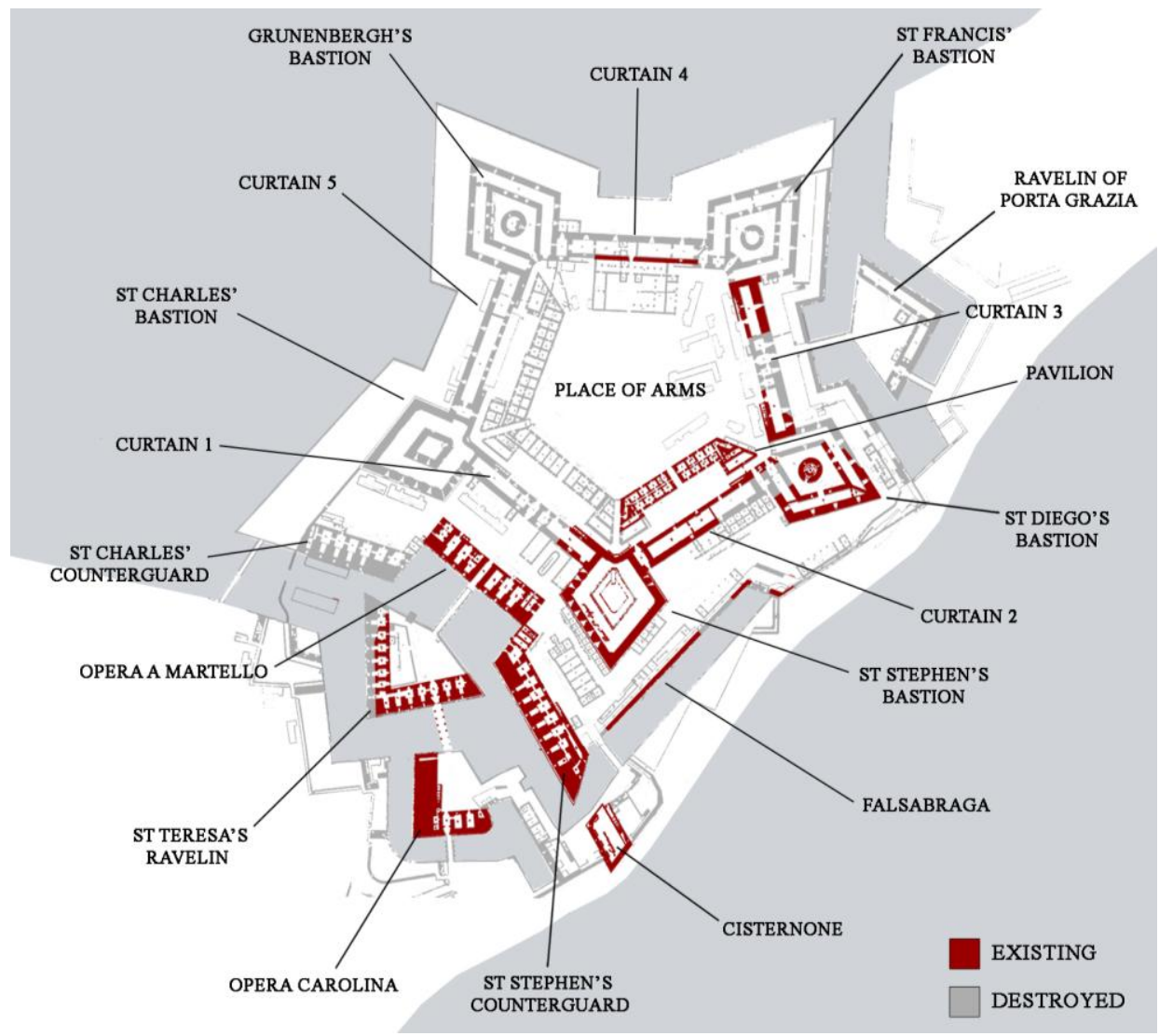

Fig. 5- Actual situation of the Royal Citadel (Image of the authors, 2014) 
led to the hypothesis of the presence of a ground of good lift to a depth of $4,5 \mathrm{~m}$; these assumptions could confirm the existence of piling foundations, as mentioned in the previous paragraph.

For a more complete knowledge of the fortification and going on the planning stages of Restoration and Reuse, an accurate survey of the existing materials and the conservative state of the existing situation was conducted, hypothesizing the primary causes of degradation and alteration. The proximity to the sea and therefore the brackish and unfavorable microclimatic conditions are the main sources of degradation of the factory and its materials. In particular, among the natural stones, blanks or processed crude, are highlighted several typical limestone of Messina, such as Polipai Limestone, and the Stone of Syracuse, especially employed in sculptured and decorated elements.

The survey also shows the presence of a collapse of the buildings still in place, although manifested in considerable time and originating from a seabed subsidence directed towards the sea, due to the presence of the low bearing capacity of the soil. This affects the overall behavior of the entire fortification since the translational motion, linked to the lowering of the soil, has also sparked riots in mutual rotation of the parts, causing deeper linear lesions in the top of the vaulted roofs.

On the base of data and knowledge gained up to this point hypotheses of intervention were developed on the entire project area.

\section{Project Work}

The Royal Citadel of Messina defined an era and has branded the city; this was meant to evoke the essence of the project proposal, by focusing it on a critical Reintegration of the Image, with the unique purpose of carrying on a project of Restoration and Compatible Reuse able to reclaim a so significant artifact and return it to the city.

\subsection{Restoration of the existing parts}

The starting point is the proposal of a structural consolidation of the remaining portions, aimed at no destabilizing the current condition of balance. Therefore minimal operations of the only decayed parts are hypothesized, consolidating foundations, with wall stitching and injections of compatible mortar in the damaged and disintegrated masonry. Interventions of pre-consolidation, cleaning, consolidation and protection are suggested for the surfaces by reintegrating the plaster lime, but in below wire where lacking, and preserving existing ones, even if detached or degraded.

\subsection{Reintegration of Image}

More radical interventions, but in line with the principles above, concern the proposal to retrace and propose again the ancient image of the Royal Citadel. The original stellar plan is brought back to light through the archeological excavations that will restore the no longer existing traces of the volumes. In the surviving intact factories, dismembered or mutilated, after
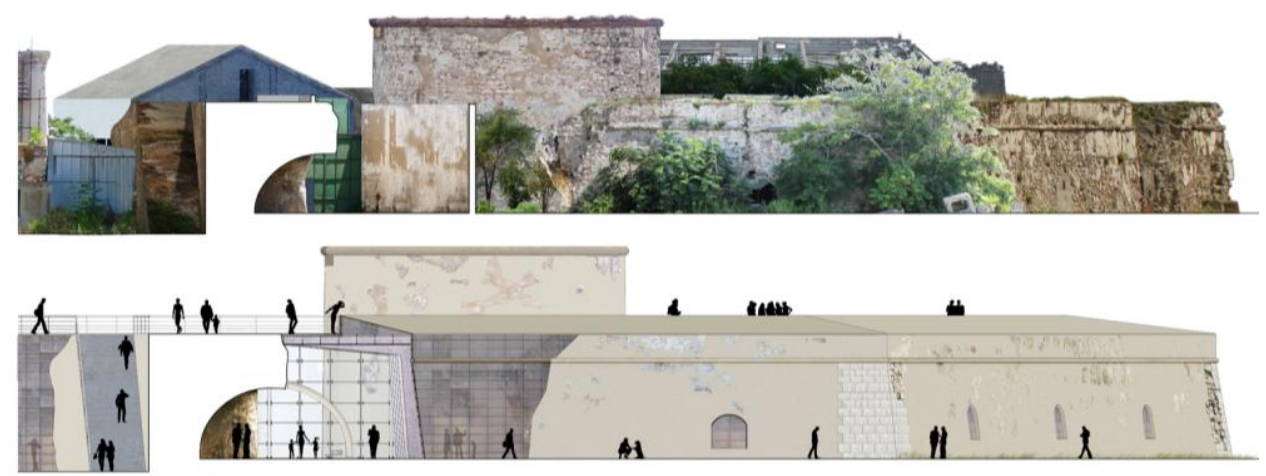

Fig. 6- Above, the current state of St Diego's Bastion, under, its restoration (Image of the authors, 2014) 
the consolidation, all the authentic material will be preserved and the volume reconfigured with a language now coextension or "projectual philology" or "conservative accompanying".

The reconfiguration of the volumes no longer existing is hypothesized with materials that maintain continuity with the original context without prevailing on it. For this reason two solutions were chosen, also related to the elements to reconstitute: the first solution, such as in the Temple of Apollo in Veio, is applied on some portions of the archaeological excavations, as the Grunenbergh's Knight, visually reconstructing the volume with a metal skeleton; the second solution, inspired by the Italian Pavilion at EXPO Exhibition in Shanghai, is directed to reintegration of the image through the use of I.Light panels for the reconstruction of the dismembered portions of the Citadel, such as Curtains and a part of the St Diego's Bastion, being very careful in the parts in contact between the new and old one so that the first part won't degrade the second one.

The I.Light panels are semitransparent

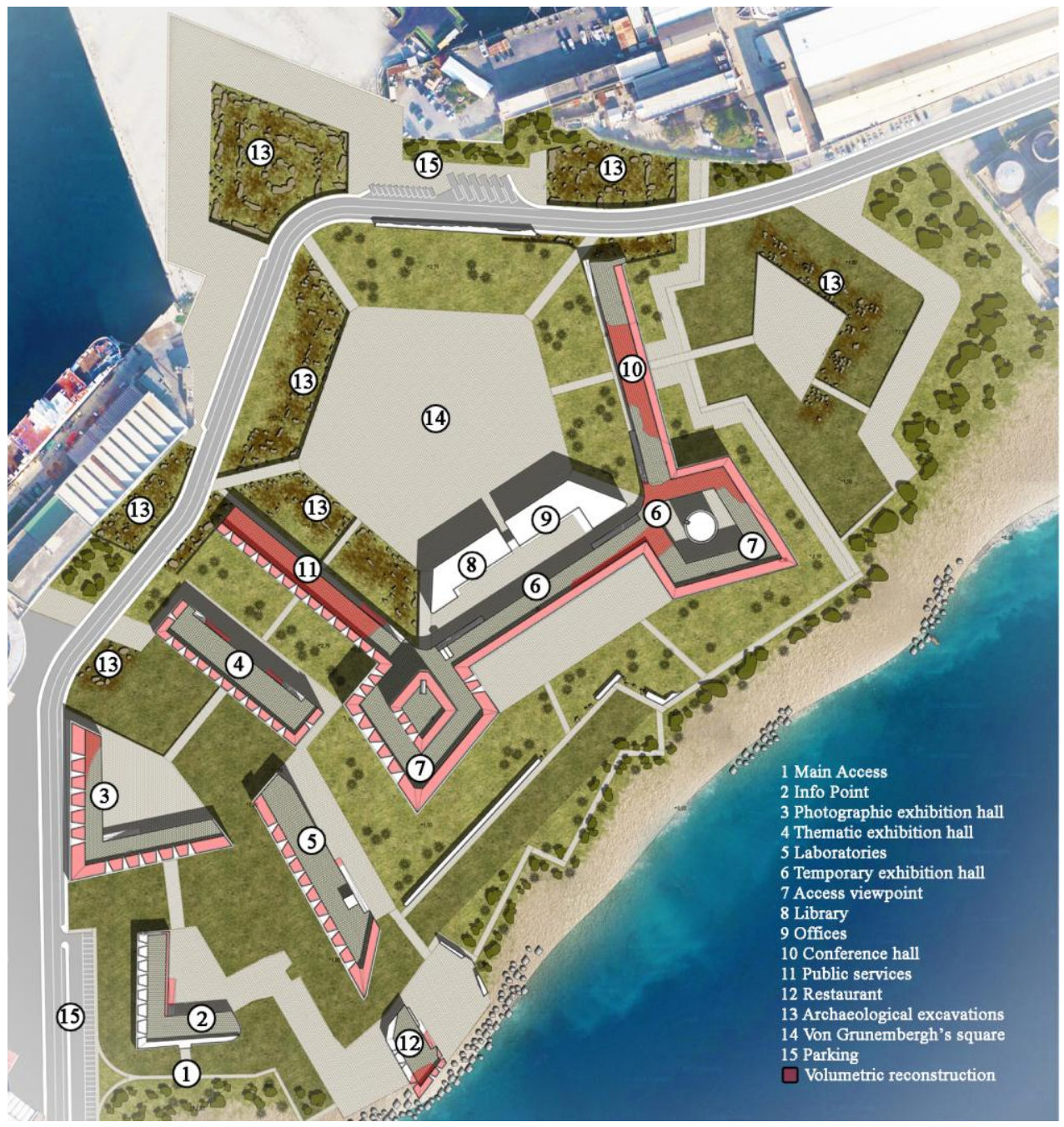

Fig. 7- Masterplan of the Project Work (Image of the authors, 2014) 


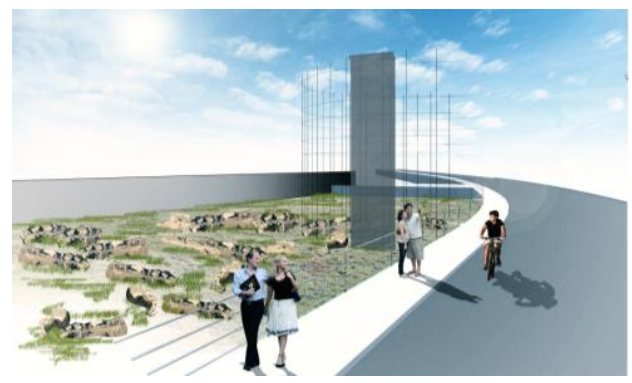

Fig. 8- The rests of St Francis's Bastion and the metal structure of the Knight (Image of the authors, 2014)

prefabricated concrete elements, consisting of a matrix of cement resin and special resins; their composition allows at the same time to filter the light and receiving the vision of objects located beyond the coating, thereby creating a very surprising effect. From the point of view of energy efficient, the panels are a good option for the coating of new constructions since they possess a low thermal transmittance, although their ability to filter the light.

The rules of giving an immediate interpretation of the original canals of water is assigned to the vegetation, diversifying it from the one in the Place of Arms, and the idea to recall the ancient pathways is defined by a careful choice of the lining of the floors.

\section{Conclusions}

The studies carried out, aimed at developing the knowledge and the historical-critical comprehension of the investigated buildings and oriented to the interpretation of conservative requests coming from the same works, have established the base on which was carried on the hypothesis of the architectural restoration. Guidelines and methodological indications were clearly defined as in the approach to restoration as in the awareness that this difficult but really challenging operation needs conceptual strictness and practical spirit, being comprehensive and having a mental balance.

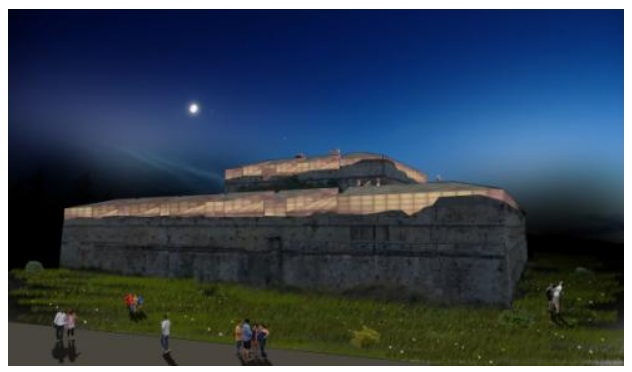

Fig. 9- Rendering of St. Stephen's Bastion with the I. Light solution (Image of the authors, 2014)

The Royal Citadel of Messina is nowadays an artifact that could and must be subjected to restoration measures in order to allow its conservation, transmission to the future and to use, especially, to give back to the population of Messina that part of the city, the sickle area, which represents their origin and all their history, reset in the last century and for this reason unknown to the majority.

\section{References}

Aricò N. (2005) "Carlos de Grunenbergh e le città ioniche del "Teatro geográfico antiguo y moderno del Reyno de Sicilia" (1686)" in Lexicon: storie e architettura in Sicilia. DiSPA. Palermo.

Catalioto Salvo A.P. (1991) Messina com'era oggi: topografia ed immagini della sua storia. EDAS. Messina.

Resta C., Aricò N., Manganaro M., Bacci G. Maria, Prestianni Giallombardo A. M., Martino F., D'Angelo M., Saija M., La Spada E., Arena G., Signorino G., Panella L., Sprizzi P., Nigrelli Carmelo F. e Fiandaca O. (2002) La penisola di San Raineri. Diaspora sull'origine, D.R.P Dipartimento di Rappresentazione e Progetto dell'Università di Messina. Rassegna di studi e ricerche. Messina.

Riccobono F., Berdar A. y C. La Fauci, (1988) La Real Cittadella di Messina. EDAS. Messina.

Sisci R., Chillemi F. y M. Lo Curzio, (1990) Messina fortificazioni e arsenali: strutture storiche e realtà urbana. Provincia regionale di Messina - Assessorato alla pubblica istruzione. Messina. 